\title{
BIBLIOGRAFIA SOBRE AMÈRICA LLATINA
}

Araujo, Ana. Hacia una identidad latinoamericana. Los movimientos de mujeres en Europa y América Latina, a «Nueva Sociedad», pp.89-99, Caracas, Jul-Ago/1985.

Bachetta, Víctor. Cambios geopolíticos en América Latina, a «Cuadernos del Tercer Mundo", pp.82-89, México, Mar/1987.

Barrera, Manuel. El movimiento de los excluidos. Desempleo y nueva informalización, a «Nueva Sociedad», pp.126-133, Caracas, JulAgo/1987.

Benítez Manaut, Raúl. Narcotráfico y terrorismo en las relaciones interamericanas, a «Polémica», pp.2-20, San José, Mayo-Ago/1988.

Bifani, Patricia. Opresión y poder. La mujer del Tercer Mundo, a «Nueva Sociedad», pp.52-60, Caracas, Jul-Ago/1987.

Brandt, Willy. Desarrollo, deuda y desarme. Los grandes retos para la paz, a «Nueva Sociedad», pp.146-150, Caracas, Sept-Oct/1984.

Briones, Álvaro. El Tercer Mundo en la perspectiva latinoamericana, a «Estudios Internacionales», pp.335-370, Santiago, Jul-Sep/1986.

Brunner, José Joaquín. El caso de la sociología en Chile. Formación de una disciplina, Santiago, FLACSO, 1988.

Bustos Ramírez, Juan. Grupos Sociales y opción democrática en América Latina, Madrid, Fundación Sistema, 1984.

Caballero, Manuel. Tormentosa historia de una fidelidad; el comunismo latinoamericano y la URSS, a "Nueva Sociedad», pp.78-85, Caracas, 1985.

Caballero, Manuel. Una falsa frontera entre la reforma y la revolución. La lucha armada en Latinoamérica, a «Nueva Sociedad», pp.141-162, Caracas, May-Jun/1987.

Cardoso, Fernando H. La democracia en América Latina, a «Síntesis», pp.11-30, Madrid, May-Ago/1987.

Castells, Manuel. La base social del populismo urbano: los pobladores y el estado en América Latina, Madrid, Alianza Ed., 1983.

Cavarozzi, M.A. i Garreton, M.A. Muerte y resurrección - los partidos politicos en el autoritarismo y las transiciones del Cono Sur-, Santiago, FLACSO, 1989.

CEPAL. La población latinoamericana: cambios en la estructura por edades, a «Notas sobre la economía y el desarrollo", pp.1-7, Santiago, Nov/1987.

Coraggio, José Luis. Poder local, poder popular, a "Cuadernos del CLAEH», pp.11-119, Montevideo, Agosto/1988. 
«Papers»: Revista de Sociologia

Cueva, Agustín. Los límites de la democracia en América Latina (notas para una discusión), a «Polémica», pp.60-67, San José, Ene-Abr/1987.

Dieterich, H. El terrorismo de estado en América Latina, a "Cristianismo y Sociedad», pp.31-64, México, 1-3/1984.

Diversos autors. Caminos de la democracia en América Latina, Madrid, Editorial Pablo Iglesias, 1984.

Diversos autors. Crisis y regulación estatal: dilemas de politica en América Latina y Europa, Buenos Aires, Grupo Editor Latinoamericano, 1986.

Diversos autors. El control político en el cono sur, México, Siglo XXI editores, 1978.

Diversos autors. Sistemas electorales y representación politica en Latinoamérica, Madrid, Fundación Ebert e ICI, 1986.

Dussel, Enrique. El factor religioso en el proceso revolucionario latinoamericano, a "Cristianismo y Sociedad», pp.41-55, México, 1/trim/1987.

Ezcurra, Ana María. El Vaticano y la Administración Reagan. Convergencias en Centroamérica, México, Nuevomar, 1984.

Faletto, Enzo. Cultura política y conciencia democrática, a "Revista de la CEPAL», pp.77-81, Santiago, Agost/1988.

Fauriol, Georges. Latin American Insurgencies, Washington, National Defense University press, 1985.

Fernández Baeza. La intervención militar en la política en América Latina, a «Revista de Estudios Políticos», pp.197-220, Madrid, 1985.

Gandini, Rosamaria. Quale futuro per gli indios?, a «Terzo Mondo Informazioni», pp.30-39, Torino, Oct/1987.

Gochman, Charles S. i RAY, James Lee. Structural disparities in Latin America and Eastern Europe, 1950-1970, a «Journal of Peace Research», n.3, vol.XVI, pp.231-254, 1979.

Godio, Julio. Democratizar el poder en la empresa. Hacia nuevas plataformas sindicales, pp.56-64, Caracas, Jul-Ago/1988.

Godio, Julio. El movimiento obrero latinoamericano 1960-1980. Diagnósticos $y$ perspectivas, a «Latinoamerica, anuario de estudios latinoamericanos", pp.197-251, México, 1985.

Green, Raul. Modes de consommation et echanges alimentaires en Amerique Latine: Bresil, Mexique et Venezuela, a «Problemes d'Amerique Latine», pp.41-64, Paris, 3/1986.

Harris, Olivia. Donne latino-americane: uno sguardo d'insieme, a «Terzo Mondo Informazioni", pp.37-47, Torino, Mar/1987.

Harris, Richard. Marxism and the transition to socialism in Latin America, a «American Perspectives», pp.7-53, Newbury Park, Winter/1988.

Hinkelammert, Franz. Democracia y nueva derecha en América Latina, a «Nueva Sociedad», pp.104-115, Caracas, Nov-Dic/1988. 
Iglesia, Juan Pablo de la. Las relaciones entre la Europa de los doce y América Latina. Un proceso de cambio acelerado, a «Pensamiento Iberoamericano", pp.137-160, Madrid, Ene-Jun/1988.

IRELA (ed.). Las implicaciones políticas de la deuda externa de América Latina, Madrid, IRELA, Dic/1986.

Jaworski, Helan. La multinazionale della droga: il caso dell'America Latina, a «Politica Internazionale», pp.129-137, Roma May/1987.

Kirsch, Henry. La juventud universitaria como actor social en América Latina, a «Revista de la CEPAL», pp.193-204, Santiago Ago/1986.

Klaveren, Alberto. Enfoques alternativos para el estudio del autoritarismo en América Latina, a «Revista de Estudios Políticos», pp.23-52, Madrid, Mai-Jun/1986.

Koval, B.. América Latina: la revolución y la época actual, Moscú, Editorial Progreso, 1987.

Lazarte, Rolando. El éxodo hacia la metrópoli. Migración interna y mercado de trabajo, a «Nueva Sociedad», pp.118-125, Caracas, Jul-Ago/1987.

Lechner, Norbert (comp.). Cultura política y democratización, Santiago, FLACSO, 1987.

Lechner, Norbert. De la revolución a la democracia. El debate intelectual en América del Sur, a «Síntesis", pp.11-23, Madrid, Ene-Abr/1987.

Lechner, Norbert. Los patios interiores de la democracia, Santiago, FLACSO, 1988.

Lindhal, Goran. El presidencialismo en América Latina y Uruguay, a «Cuadernos del CLAEH", pp.109-123, Montevideo, Dic/1987.

Maira, Luis. Predicciones y realidades acerca de la democracia y el cambio social en América Latina, a «Síntesis», pp.31-38, Madrid, May-Ago/1987.

Mires, Fernando. ¿Adiós a los comunistas? Esquemas para una bistoria del movimiento comunista latinoamericano, a «Perspectivas, Revista de Teoría y Análisis Político", pp.41-71, Paris, 1987.

Mires, Fernando. Continuidad y ruptura en la política latinoamericana, a "ALAI", pp.19-24, Montreal, Ago/1987.

Mols, Manfred. La responsabilidad europea en el proceso latinoamericano de redemocratización: una perspectiva alemana, Madrid, IRELA, 1988.

Muñoz, Heraldo. El estudio de las politicas exteriores latinoamericanas: temas y enfoques dominantes, a «Estudios Internacionales», pp.406-434, Santiago, Oct-Dic/1987.

Muñoz, Heraldo (comp.). Las políticas exteriores latinoamericanas frente a la crisis, Buenos Aires, Grupo Editor Latinoamericano, 1985.

O'Donnell, Guillermo. América Latina, Estados Unidos, Democracia: variaciones sobre un viejisimo tema, a «Síntesis», pp.115-136, Madrid, MayAgo/1987. 
«Papers»: Revista de Sociologia

Pansters, Wil. Urban social movements and political strategy in Latin America, a «Boletín de Estudios Latinoamericanos y del Caribe», pp.1327, Amsterdam, Dic/1986.

Pasara, Luis. Latinoamerica y las relaciones con Estados Unidos, a "Polémica», pp.38-50, San José, Sep-Dic/1988.

Pasquini, Giancarlo. América Latina: la democracia difícil, a «Leviatán», pp.77-88, Madrid, Prim-Verano/1986.

Pease, Henry. La posibilidad democrática en América Latina, a "Leviatán», pp.121-133, Madrid, 1988.

Perina, Rubén i Ramírez, Norma. La importancia de América Latina en el sistema internacional en la década de los ochenta: un ensayo bibliográfico, a «Estudios Internacionales», pp.184-205, Santiago, Abr-Jun/1988.

Petras, James. Clase, Estado y poder en el Tercer Mundo. Casos de conflictos de clases en América Latina, México, Fondo de Cultura Económica, 1986.

Pollack, Benny. Enfoques sobre los regímenes autoritarios en América Latina, Madrid, Fundación Sistema, 1984.

Rama, Germán W. i Faletto, Enzo. Sociedades dependientes y crisis en América Latina: los desafios de la transformación politico-social, a «Revista de la CEPAL», pp.127-145, Santiago, Abr/1985.

Saldomando, Ángel. La socialdemocracia en América Latina, a «Perspectivas, Revista de teoría y análisis político», pp.38-59, Paris, Dic/1986.

Spalding, Hobart. Unions Look South, a «Nacla, Report on the Americas», pp.14-19, New York, 1988.

Tella, Torcuato di. Las perspectivas de la evolución politica y social de América Latina, a "Revista de la CEPAL", pp.91-101, Santiago, Ago/1985.

Touraine, Alain. Questions en debat, les chances de la democratie en Amerique Latine, a «Problemes d'Amerique Latine», pp.119-133, Paris, 1986.

Varas, Augusto (ed.). Transición a la democracia, Santiago, ACHIP, Dic/1984.

Vilas, Carlos. El populismo latinoamericano: un enfoque estructural, a «Desarrollo económico», pp.323-351, Buenos Aires, Oct-Dic/1988.

Vitale, Luis. Historia y sociología de la mujer latinoamericana, Barcelona, Fontamara, 1981.

Weffort, Francisco C. Los dilemas de la legitimidad política, a «Revista de la CEPAL ", pp.125-141, Santiago, Agost/1988.

Wolf, Ulrike. Bibliography of Western European-Latin American relations, Madrid, IRELA, 1986. 